Obstructive sleep apnoea

\section{Are oral appliances a substitute for nasal positive airway pressure?}

\section{R P Millman, C L Rosenberg}

\section{A simple non-adjustable oral appliance is no substitute for nasal positive airway pressure in patients with obstructive sleep apnoea.}

A though positive airway pressure (PAP) devices have become the mainstay of treatment for obstructive sleep apnoea, not all patients can or will use PAP on a nightly basis. Many patients find taking a bulky PAP unit on business or vacation trips a burden. In this issue of Thorax Smith and Stradling attempt to show that a simple nonadjustable oral appliance may be used in place of PAP on a short term basis. ${ }^{1}$ Unfortunately, in only nine of the 50 patients entered into the study was their sleep apnoea controlled with the appliance.

This low success rate of $18 \%$ does not concur with the published literature which has reported a success rate of $81 \%$ in patients with mild and $60 \%$ in patients with moderate sleep apnoea. ${ }^{2}$ Part of the difference between this study and the previous literature may be related to the type of device used and side effects from the device. Smith and Stradling employed a device that had previously been shown to be effective in controlling snoring. ${ }^{3}$ It consists of two customised sports-type mouth guards fused together to place the mandible in a forward position set at approximately $75 \%$ of maximum mandibular protrusion. The device covers both the teeth and the gums, so it differs from more commonly used devices such as the Herbst and the Klearway which cover only the teeth and are adjustable, allowing gradual advancement of the mandible to a forward position at night to open the pharynx and prevent snoring and sleep apnoea.

The difference in appliance configuration probably contributed to the low success rate. Thirty one of the subjects studied by Smith and Stradling gave up the device due to intolerable side effects such as sore gums, excessive salivation, and painful masseter muscles or temporomandibular joints. This contrasts markedly with other experiences with the appliance. We previously reported a study of 19 patients who had failed with nasal CPAP and changed to treatment with the Herbst mandibular advancement device. ${ }^{4}$ At the time of the follow up sleep studies no patient reported pain or discomfort while wearing the removable Herbst appliance. Tegelberg and colleagues reported 45 patients randomised to treatment with an oral appliance adjusted to $50 \%$ of maximum mandibular protrusion. ${ }^{5}$ Only one patient withdrew from treatment for side effectsspecifically, the patient developed recurrent aphthous ulcers related to an allergic reaction to the acrylic polymer. Fritsch et al randomised patients to treatment with either a Herbst appliance or an appliance developed at their centre (Monobloc) initially set at $75 \%$ maximum mandibular protrusion. ${ }^{6}$ Although side effects were common with the two appliances (mucosal dryness, tooth discomfort, and excessive salivation), all the symptoms were mild and none of the subjects discontinued treatment because of side effects. Mehta and colleagues randomised 28 patients to treatment either with a control oral plate that did not advance the mandible or with a mandibular advancement split that advanced the mandible to the most protrusive position that the patient could comfortably maintain. ${ }^{7}$ Twenty one of the 24 patients completed the protocol. Side effects, which included excessive salivation, gum irritation, mouth dryness, jaw discomfort, and tooth grinding were mild to moderate and lasted a maximum of 3 weeks. None of the patients stopped using their device because of the side effects. Furthermore, two randomised crossover studies of PAP and oral appliances have shown that mandibular advancement was better tolerated in mild to moderate sleep apnoea and preferred to nasal PAP. ${ }^{89}$

Even in those patients who were able to tolerate their mandibular advancement device, Smith and Stradling found that their sleep apnoea was not well controlled with the appliance. One reason may have been that the patients did not have their appliances suitably adjusted.
The authors arbitrarily chose a specific mandibular protrusion and then studied the patients at that setting. Setting a mandibular position for an oral appliance may not be that simple. Kato et al reported a dose-dependent effect of mandibular advancement on the severity of sleep apnoea. ${ }^{10}$ Clinical protocols in patients with adjustable Herbst or Klearway appliances involve a slow advancement of the mandible until snoring and daytime sleepiness have resolved. At this point patients using an appliance are sent for repeat polysomnographic evaluation to see if further adjustments need to be made to the appliance. In our clinic patients on nasal CPAP who would like to use an appliance for vacation or business trips are not allowed to switch to an appliance unless it is adequately controlling their sleep apnoea. One could argue that giving an appliance with an arbitrarily fixed mandibular protrusion to a patient with sleep apnoea is akin to arbitrarily switching a patient with an appliance to an arbitrary PAP pressure of, for example, 8 or $10 \mathrm{~cm} \mathrm{H}_{2} \mathrm{O}$.

The response of a patient to an oral appliance may also be affected by pharyngeal anatomy; this is not mentioned by Smith and Stradling. Patients with large tonsils, for example, may not respond to an oral appliance because of the degree of baseline pharyngeal obstruction. In a series of patients who had failed uvulopalatopharyngoplasty and who then went on to oral appliance therapy, we reported one patient in whom an oral appliance did not control his sleep apnoea. ${ }^{11}$ On initial testing he had a baseline apnoeic/hypopnoeic index (AHI) of 43 episodes/hour. Since he could not tolerate nasal CPAP he was fitted with a Herbst appliance. The repeat AHI with the Herbst appliance in place was 56 episodes/hour. Because he was significantly symptomatic he underwent a uvulopalatopharyngoplasty, following which the AHI was 29 episodes/hour. He was then tried on the appliance again and a repeat sleep study indicated control of his sleep apnoea with an AHI of 8 episodes/hour.

In summary, Smith and Stradling have shown that, in their hands, their appliance was not a good alternative to PAP therapy. Their results were hampered by significant side effects from the appliance and poor control of the sleep apnoea. Although it is possible that their results could be extended to bite-block type appliances, it is difficult to extrapolate the results to more sophisticated adjustable mandibular devices.

Thorax 2002;57:283-284

\section{Authors' affiliations}

R P Millman, C L Rosenberg, Departments of Medicine and Plastic Surgery, Rhode Island 
Hospital, Brown Medical School, Providence, Rhode Island, USA

Correspondence to: Dr R P Millman, Division of Pulmonary, Sleep and Critical Care Medicine Rhode Island Hospital, 593 Eddy Street (APC-4), Providence, RI 02903, USA;

Rmillman@Lifespan.org

\section{REFERENCES}

1 Smith DM, Stradling JR. Can mandibular advancement devices be a satisfactory substitute for short term use in patients on nasal continuous positive airway pressure? Thorax 2002;57:305-8.

2 Marklund M, Franklin KA, Sahlin C, et al. The effect of a mandibular advancement device on apneas and sleep in patients with obstructive sleep apnea. Chest

1998; 113:707-13.
3 Stradling JR, Negus TW, Smith D, et al. Mandibular advancement devices for the control of snoring. Eur Respir J 1998;11:447-50

4 Eveloff SE, Rosenberg CL, Carlisle CC, et al. Efficacy of a Herbst mandibular advancement device in obstructive sleep apnea. Am J Respir Crit Care Med 1994; 149:905-9.

5 Tegelberg A, Wilhelmsson BO,

Walker-Engstrom ML, et al. Effects and adverse events of adental appliance for treatment of obstructive sleep apnoea. Swed Dent J 1999;23: 117-26.

6 Fritsch KM, Iseli A, Russi EW, et al. Side effects of mandibular advancement devices for sleep apnea treatment. Am J Respir Crit Care Med 2001;164:813-8.

7 Mehta A, Qian J, Petocz P, et al. A randomized, controlled study of a mandibular advancement splint for obstructive sleep apnea. Am J Respir Crit Care Med 2001;163:1457-61.
8 Ferguson KA, Ono T, Lowe AA, et al. A randomized crossover study of an oral appliance vs nasal-continuous positive airway pressure in the treatment of mild-moderate obstructive sleep apnea. Chest 1996; 109: 1269-76.

9 Bloch KE, Iseli A, Zhang JN, et al. A randomized, controlled crossover trial of two oral appliances for sleep apnea treatment. Am J Respir Crit Care Med 2000;162:246-51.

10 Kato J, Isono S, Tanaka A, et al. Dose-dependent effects of mandibular advancement on pharyngeal mechanics and nocturnal oxygenation in patients with sleep-disordered breathing. Chest 2000;117: 1065-71.

11 Millman RP, Rosenberg CL, Carlisle CC, et al. The efficacy of oral appliances in the treatment of persistent sleep apnea after uvulopalatopharyngoplasty. Chest 1998; 113:992-6.

\section{Vocal cord dysfunction and laryngeal hyperresponsiveness: a function of altered autonomic balance?}

\section{J G Ayres, P L A Gabbott}

\section{The interrelationships between vocal cord dysfunction and laryngeal hyperresponsiveness may have profound implications in the diagnosis and management of patients with difficult respiratory symptoms.}

7 he ability of land animals to oxygenate via the lung as they developed from aquatic species means that a system also evolved for protecting the lung from flooding-the glottis. Although in man this is considered primarily as an organ of speech, disturbance of its protective function will threaten the integrity of the lung. While obstructive conditions in the larynx can cause breathlessness, abnormal function of an otherwise structurally normal larynx can also lead to symptoms. Such a condition is vocal cord dysfunction, characterised by paradoxical movement of the vocal cords resulting in marked reductions in airflow and breathlessness. ${ }^{1}$

During normal respiration the false vocal cords move very little while the true cords abduct slightly during both inspiration and expiration. ${ }^{2}$ In vocal cord dysfunction, paradoxical movement of the true and/or false cords occur during inspiration, expiration, or both. ${ }^{23}$ Vocal cord dysfunction frequently co-exists with asthma ${ }^{45}$ and is usually considered as being exclusively associated with psychopathology, ${ }^{14}$ a view which is perpetuated in part by the diagnosis only being considered in that situation. However, vocal cord dysfunction can occur in psychologically normal patients-for example, after upper respiratory tract infections ${ }^{6}$ or thyroid surgery. ${ }^{7}$ Diagnostic confirmation is not always easy. The flow-volume loop may reveal either extrathoracic upper airway obstruction or ending of the inspiratory limb below total lung capacity, ${ }^{9}{ }^{10}$ while direct visualisation of the cords may detect paradoxical cord adduction but usually only after exposing the subject to a known trigger such as perfume. ${ }^{11}$ However, both these methods have low sensitivity, albeit high specificity.

\section{LARYNGEAL \\ HYPERRESPONSIVENESS}

Laryngeal hyperresponsiveness (analogous to bronchial or nasal hyperresponsiveness in asthma or allergic rhinitis) shown by Bocca et al. ${ }^{12}$ They found laryngeal hyperresponsiveness in the majority of patients who presented with recurrent episodes of wheeze by showing deformation of the changes in the flow-volume loop after histamine challenge, although the reproducibility of this measure can may underlie vocal cord dysfunction, as be questioned. However, inhalation of histamine or methacholine has been shown to cause laryngeal narrowing in both normal and asthmatic subjects (using photography, ${ }^{13}$ fluoroscopy, ${ }^{14}$ or laryngeal sounds ${ }^{15}{ }^{16}$ ) and in those with acute severe asthma ${ }^{1417}$ and with chronic asthma on exercise. ${ }^{18}$ Conversely, laryngeal widening occurs in normal subjects following mechanical stimulation $^{19}$ and in both normal and mild asthmatic subjects on exercise ${ }^{18}$ and during panting. ${ }^{14}{ }^{20}$ Panting overrides the glottic narrowing induced by methacholine in stable asthma but not that seen in acute severe asthma. ${ }^{14}$ Inflammatory and irritant stimuli can thus cause a transient or a longer lasting tendency to laryngeal narrowing - that is, laryngeal hyperresponsiveness-which will thus contribute to wheezy breathlessness. In addition, antigen handling cells can be found in the laryngeal mucosa, ${ }^{21}$ which suggests that allergens may be important in the development of laryngeal hyperresponsiveness. However, the presence of inflammation alone does not explain why this irritable state is maintained over time.

\section{ALTERED AUTONOMIC BALANCE}

An altered state of autonomic balance, maintained by the activity of more central brain regions with the potential strongly to influence autonomic function, could underlie this response. These areas include sites in the medulla, midbrain and the prefrontal cortex, particularly medial areas 25 and 32 of Brodmann, ${ }^{22}$ and are polysynaptically linked with the larynx. Both true and false vocal cords derive motor innervation from the vagus, while sensory fibres from M3 muscarinic receptors (among others) in the laryngeal mucosa ${ }^{23}$ pass via the vagus to the medulla. Activity within these areas directly influences autonomic functions such as the respiratory and cardiac cycles and gut motility. 
Area 25 also receives inputs resulting from a variety of factors such as stress, emotion, and changes in ambient temperature, and is thus well positioned to act as a modulator of autonomic output in response to inputs both from sensory mucosal nerves and to these less specific inputs. ${ }^{24} 25$

But what evidence is there for an altered autonomic preset in certain individuals? Asthmatic subjects exposed to sulphur dioxide at rest show a reduction in parasympathetic tone while normal subjects show an increase in tone, ${ }^{26}$ perhaps mediated through rapidly adapting receptors ${ }^{27}$ in the larynx. ${ }^{28}$ While such an increase in vagal tone in normal subjects in response to an inhaled irritant can be construed as bronchoprotective, this apparently paradoxical asthmatic response may be due to an initial induction of neurogenic inflammation by the irritant followed by vagal inhibition. ${ }^{26}$ Once upper airway hyperresponsiveness (on the background of the change in autonomic preset) is established, the absence of quick recovery from an initiating episode could result in this autonomic preset becoming persistent. Subsequent further irritant stimuli would prevent or slow recovery leading to persistent symptoms.

\section{VOCAL CORD DYSFUNCTION}

Clinically, vocal cord dysfunction often overlaps with the hyperventilation syndrome, a condition also deemed to be largely psychological in origin ${ }^{29}$ in which tachypnoea could be explained by the presence of laryngeal hyperresponsiveness and consequent glottic narrowing. Vocal cord dysfunction can mimic or co-exist with severe asthma ${ }^{15}$ and apportioning the symptoms of the two can be difficult. Preliminary findings in severe asthma $^{30}$ suggest that the increase in parasympathetic tone on lying flat is exaggerated in severe asthma compared with mild asthma, which could contribute to nocturnal symptoms in asthma and in vocal cord dysfunction.

Vocal cord dysfunction may thus be caused by laryngeal hyperresponsiveness, initiated by an initial inflammatory insult and resulting in altered autonomic balance which may be short lived or become persistent. If persistent, subsequent stimuli (such as psychological stressors or cold air) will induce local parasympathetic reflexes causing airway narrowing either at the glottic level and/or in patients with asthma in the lower airways. As such, this represents an exaggeration of the role of the larynx in lung protection. The altered autonomic preset is likely to be primarily driven by the highest centres of the central nervous system such as area 25 of the prefrontal cortex. These complex interrelationships now need to be explored, as this may have profound implications in the diagnosis and management of patients with difficult respiratory symptoms.

Thorax 2002;57:284-285

\section{Authors' affiliations}

J G Ayres, Department of Respiratory Medicine, Birmingham Heartlands Hospital, Bordesley Green East, Birmingham B9 5SS, UK P L A Gabbott, Department of Experimental Pyschology, South Parks Road, Oxford OXI 3UD, UK

Correspondence to: Professor J G Ayres, Department of Respiratory Medicine, Birmingham Heartlands Hospital, Bordesley Green East, Birmingham B9 5SS, UK; ayresj@heartsol.wmids.nhs.uk

\section{REFERENCES}

1 Newman KB, Mason UG, Schmaling KB. Clinical features of vocal cord dysfunction. Am J Respir Crit Care Med 1995;152:1382-6.

2 England SJ, Bartlett D, Daubenspeck J A. Influence of human vocal cord movements on airflow and resistance during eupnea. J Appl Physiol Respirat Environ Exerc Physiol 1982;52:773-9.

3 Christopher KL, Wood RP, Eckert RC, et al. Vocal cord dysfunction presenting as asthma. N Engl J Med 1983;308:1566-70.

4 Mobeireek A, Alhamad A, Al-Subaei A, et al. Psychogenic vocal cord dysfunction simulating bronchial asthma. Eur Respir 1995;8:1978-81

5 Thomas PS, Geddes DM, Barnes PJ. Pseudo-steroid resistant asthma. Thorax 1999;54:352-6.

6 Campbell AH, Mestitz H, Pierce R. Brief upper airway (laryngeal) dysfunction. Aust NZ I Med 1990;20:663-8.

7 Harbison J, Dodd J, McNicholas WT. Paradoxical vocal cord motion causing stridor after thyroidectomy. Thorax 2000;55:533-4.

8 Schwartz AR, Smith PL, Kashima HK, et al. Respiratory Function of the upper airways. In: Murray JF, Nadel JA, eds. Textbook of respiratory medicine. $2 \mathrm{nd}$ ed. London: WB Saunders, 1994: 1451-70.

9 Cormier YF, Camus P, Desmeules M. Non-organic acute upper airway obstruction: description and a diagnostic approach. Am Rev Respir Dis 1980;121:147-50.

10 Ayres JG, Rees PJ, Cochrane GM. Haemoptysis and non-organic upper airways obstruction in a patient with previously undiagnosed Ehlers-Danlos syndrome. $\mathrm{Br} J \mathrm{Dis}$ Chest 1981;75:309-10.

11 Selner JC, Staudenmayer H, Koepke JW, et al. Vocal cord dysfunction: the importance of psychologic factors and provocation challenge testing. J Allergy Clin Immuno 1989;79:726-33.

12 Bocca C, Rolla G, Brussino L, et al. Are asthma-like symptoms due to bronchial or extrathoracic airway dysfunction? Lancet 1995:346:791-5

13 Higenbottam T. Narrowing of the glottis opening in humans associated with experimentally induced bronchoconstriction. J Appl Physiol Respirat Exerc Physiol 1980;49:403-7.

14 Collett PW, Brancatisano AP, Engel LA. Upper airway dimensions and movements in bronchial asthma. Am Rev Respir Dis 1986:133:1143-9

15 Yanai M, Ohrui T, Sekizawa K, et al. Laryngeal resistance immediately after panting in asthmatic subjects. Thorax 1989:44:743-8

16 Shindoh C, Sekizawa K, Hida W, et al. Upper airway response during bronchoprovocation and asthma attack. Am Rev Respir Dis 1985;132:671-8.

17 Lisboa C, Jardim J, Angus E, et al. Is extrathoracic airflow obstruction important in asthma? Am Rev Respir Dis 1980;122:115-21.

18 Hurbis CG, Schild JA. Laryngeal changes during exercise and exercise-induced asthma. Ann Otol Rhinol Laryngol 1991;100:34-7.

19 Michoud MC, Amyot R, Jeanneret-Grosjean $A$, et al. Reflex decrease of histamine-induced bronchoconstriction after laryngeal stimulation in humans. Am Rev Respir Dis 1987;136:618-22

20 England SJ, Bartlett D. Changes in respiratory movements of the human vocal cords during hyperpnea. J Appl. Physiol Respirat Environ. Exerc Physio 1982;52:780-5

21 Sätiblar-Martin M. Histology of the laryngeal mucosa. Acta Otolaryngol (Stockh) 1997;27(Suppl 5): 138-41.

22 van Eden CG, Buijs RM. Functional neuroanatomy of the prefrontal cortex. In: Uylings HBM, van Eden CG, de Bruin JPC, et al, eds. Cognition, emotion and autonomic responses: the integrative role of the pre-frontal cortex and limbic structures. Progress in Brain Research.Volume 126. Amsterdam: Elsevier, 2000:51-64.

23 Richardson BE, Pernell KJ, Goding GS. Effect of antagonism at central nervous system $M 3$ muscarinic receptors on laryngeal chemoresponse. Ann Otol Rhinol Laryngol 1997; 106:920-6.

24 Price JL, Carmichael ST, Drewets WC. The emotional motor system. In: Holstege $G$, Bandler R, Saper CB, eds. Progress in Brain Research. Volume 107. Amsterdam: Elsevier, 1996:523-6

25 Morris JS, Scott SK, Dolan RJ. Saying it with feeling: neural responses to emotional vocalizations. Neuropsychologia 1999;37: 1155-63

26 Tunnicliffe WS, Mark D, Harrison RM, et al. Effect of particle and sulphur dioxide challenge on heart rate variability in normal and asthmatic subjects. Eur Respir J 2001;17:604-8

27 Callanan D, Dixon M, Widdicome JG. The acute effects of sulphur dioxide on pulmonary mechanics, breathing patterns and pulmonary vagal afferent receptors in the rabbit. J Physiol 1975;247:23P.

28 Hahn HL, Fabbri L, Graf PD, et al. Bronchokonstriktion und Hypersekretion nach Schwefeldioxid $\left(\mathrm{SO}_{2}\right)$ Ein laryngealer Reflex? Prax Klin Pneumol 1983;37:666-9.

29 Gardner WN. The pathophysiology of hyperventilation disorders. Chest 1996; 109:516-34.

30 Mukhopadhyay J, Manney S, Bates R, et al. Enhanced parasympathetic tone in anxious patients with severe asthma: results from a pilot study. Thorax 2000;55:A31. 